\title{
The relationship between monochronicity, polychronicity and individual characteristics
}

\author{
R.S. GOONETILLEKE ${ }^{1 *}$ and Y. LUXIMON ${ }^{2}$ \\ ${ }^{1}$ Human Performance Laboratory \\ Department of Industrial Engineering \& Logistics Management \\ Hong Kong University of Science \& Technology \\ Clear Water Bay, Hong Kong \\ 1*Email: ravindra@ust.hk \\ 2Email: sdtina@polyu.edu.hk
}

Submitted to Behaviour \& Information Technology on May 2009 


\begin{abstract}
With the increasing complexity of control rooms and the information explosion, effective multitasking is now desired. Monochronicity and polychronicity, which describe a person's ability to do one thing and many things at a time, respectively, have been studied for a long time. However, it is not clear these abilities are related to various individual characteristics. Forty-eight Chinese participants were tested on their perception, memory, judgment, attention ability and cognitive style. They also performed a task that required search and calculation under three conditions of unpaced, paced, and paced with sequencing. There were significant differences in the performance and strategy between monochronic and polychronic individuals in the selective attention test. Monochronic individuals focused their attention on the primary task and achieved higher performance. Polychronic individuals had somewhat better total performance in more than one task under time-constrained conditions. The results clearly indicate that an individual's time use behaviors ought to be considered in training and control scenarios to account for differences among people.
\end{abstract}

Running Head: monochronicity and polychronicity

Keywords: Time use; Cognitive abilities; Multitasking, Polychronicity, Individual differences, Attention 


\section{Introduction}

With the increasing complexity of the different types of control rooms and the information explosion via the web and other sources, effective multitasking has become a desired trait in some settings. In emergency situations, keeping track of several pieces of information and taking the right action at the right time can be extremely critical. Time constraints or time pressure, defined as the difference between the time available and time required for performing a task (Benson and Beach 1996, Ratsegary and Landy 1993) have become important in decision-making processes. Wickens and Hollands (2000) have proposed an information processing loop that includes many cognitive abilities such as perception, memory, judgment and attention to account for differences in task performance. When a person has to do more than one task within a given time, performance in some or all of the tasks may be affected as he or she allocates the available cognitive resources among the tasks at hand. (Wickens and Hollands 2000). Maule and Edland (1997) reviewed several studies which all suggested that time pressure reduced the quality of judgment and decision making. Moray and Rotenberg (1989) alluded to the concept of cognitive lock-up where control operators are focused on one task even when their attention is needed on other tasks. They also mentioned that cognitive processing and visual attention may influence human performance. The relationship between attention and human performance has been investigated by many (Arthur et al. 1995, Gopher et al. 1989, Mane and Donchin 1989, Frederiksen and White 1989). Multitasking is a means to accomplish many goals within a certain period of time by switching between individual tasks (Delbridge, 2000). Gopher (1992) attributed improvements in task performance to a subject's ability to switch between multiple components in a 
complex task. Not everyone is efficient in handling many tasks simultaneously. Brown et al. (1988) tested the performance of subjects copying a short paragraph while listening to a series of isolated words. They found that when attention load increased, writing speed decreased.

Hall (1959) proposed the concepts of monochronicity and polychronicity to explain the differences in task switching and time usage. Monochronicity refers to doing one thing at a time and polychronicity refers to doing many things at the same time or doing things in parallel. Over the years, the differences in time use have been determined through the development of various scales that measure monochronic and polychronic activities. These include the Modified Polychronic Attitude Index 3 (MPAI3) (Lindquist et al. 2001) and the Inventory of Polychronic Values (IPV) (Bluedorn et al. 1999).

Contrary to results presented by König et al. (2005) that showed polychronicity is not a predictor of multitasking performance, many studies have shown the effects of time-related behaviours on human performance (Conte and Gintoft 2005, Haase et al. 1979, Madjar and Oldham 2006, Zhang et al. 2005). Haase et al. (1979) mentioned an unpublished three-task experiment where monochrons (those who exhibit monochronic behaviors) demonstrated better performance in one of three tasks while polychrons (those who exhibit polychronic behaviours) had relatively similar performance in all three tasks validating that monochrons focus on one task while polychrons handle more than one task. Zhang et al. (2005) have shown that the strategy and performance of monochrons are significantly different than those of polychrons in a dual process control task. Polychrons switched between the two control processes significantly more than monochrons and had better overall performance as they were able to control both processes at the same time compared 
with monochrons, who were predominantly focused on one process for a longer time. More recently, Madjar and Oldham (2006) also found that polychrons exhibited better performance on more than one task, whereas monochrons had higher performance in sequential tasks where one task was completed prior to beginning another. Even though the performance differences between the two groups of monochrons and polychrons is evident, the underlying reasons for these differences are still not clear. Conte and Jacobs (2003) tested polychronicity with a cognitive ability measure that consisted of 40 items that tapped memory, problem sensing, deductive reasoning, inductive reasoning, verbal ability and information ordering (Fleishman 1991, Fleishman and Reilly 1992). They found a significant $(\mathrm{p}<0.05)$ but low correlation of 0.15 between cognitive ability and polychronicity. Here, we seek to determine if time-related behaviours are related to other types of cognitive abilities and to the cognitive style of a person, especially since Torenvliet et al. (2000) found that a holistic cognitive style is a good predictor of performance in an ecological interface environment. Kahneman (1973) suggested that the greater the attention people have, the better their performance when multitasking. We also tested the effects of time use, task condition and their interactions when performing many tasks. Our hypotheses were as follows:

Hypothesis 1: Monochrons are significantly different from polychrons in cognitive style and in the individual abilities of perception, memory, judgment and attention, which are all part of the information processing loop (Wickens and Hollands 2000).

Hypothesis 2: The availability of time can significantly affect the behavior and performance of monochrons and polychrons.

\section{Methodology}




\subsection{Participants}

Forty-eight students (24 monochrons and 24 polychrons) participated in this experiment. Prior to the experiment, around 300 Chinese students at the Hong Kong University of Science and Technology filled in an online version (http://143.89.20.170/intro.html) of the simplified "work and life survey” (Plocher et al. 2002), which consisted of the Modified Polychronic Attitude Index 3 (MPAI3) (Lindquist et al. 2001) and the Inventory of Polychronic Values (IPV) (Bluedorn et al. 1999). The time use of each participant was quantified using each of the two scales as the mean value of the three items of the MPAI3 scale (MPAI3 score) and the mean value of the ten items of the IPV scale (IPV score). The score range of each scale was from 1 to 7 . From these scale values, 24 participants were categorized as monochrons (that is, $1 \leq$ MPAI3 score $\leq 3$ and $1 \leq$ IPV score $\leq 3$ ), and 24 were categorized as polychrons (that is, $5 \leq$ MPAI3 score $\leq 7$ and $4.9 \leq$ IPV score $\leq 7$ ). Even though this categorization method may be considered to be an extreme groups approach (Preacher et al. 2005), the division was essential to identify the two groups of people.

\subsection{Stimulus material}

\subsubsection{Individual abilities}

The Aptitude Intelligence Test series (Perception, Memory and Judgment) available from Industrial Psychology International (IPI), Ltd (1981, 1984) (used by Goonetilleke (1990) and Wang et al. (1991)), the digit span test (modified from Goonetilleke et al. 
(1999)) and the attention test (modified from Hirshkowitz et al. (1993)) were used to determine the cognitive abilities of the subjects.

The IPI tests were all paper and pencil based. The IPI perception test, which includes words and numbers, measures the subject's ability to locate details and to recognize differences quickly. The test time was six minutes. The IPI memory test, which was six minutes was used to measure recognition and recall of visual, verbal and numerical information. The judgment test, which is designed to evaluate the aptitude to think logically and measure the ability to determine solutions to abstract problems, was also a six-minute test. The test-retest reliability of the perception, memory and judgment tests were claimed to be 0.719 (for 92 clerical employees when the test was given a second time after four months), 0.71 (for 91 employees in a large white-collar organization after approximately four months since the initial testing), and 0.811 (for 90 clerical employees with the second test performed four months after the first), respectively (IPI 1981, 1984).

A digit-span test (modified from Goonetilleke et al. (1999)) was used to check the short-term memory capability of participants. Number sequences comprising 5 to 13 digits were presented on the screen one sequence at a time. There were 18 sequences (9 variations $* 2$ repetitions) to be recalled. In each sequence, there was no repetition of digits in consecutive positions. The presentation order of variations (i.e., number of digits per sequence) and the digits in each variation was random. Each number sequence was shown for a total duration equivalent to $500 \mathrm{msec} /$ digit. In other words, if the number shown had "n" digits, the participant was able to see the number for a time of 500n msec. At the end of the allotted time, each participant was expected to recall and enter the number shown on the screen. The digit span was calculated as $4+$ Q/2 (where Q refers to the number of perfectly recalled sequences out of a total of 18) (Goonetilleke et al. 1999). 
In the attention test (modified from Hirshkowitz et al. (1993)), which was programmed using Visual Basic, targets (the letter “污”) and non-targets (the letter “ك”) were displayed on a $3 \times 3$ masking grid (册) and were shown on a computer screen. The masking grid changed to a target or non-target for 250 milliseconds and changed back to the masking grid. The inter-stimulus interval was varied, randomly, between 4 and 11 seconds, to minimize the temporal expectancy. That is, reducing any possibility of any bias of hitting the same key due to expected repetition. Three targets and five non-targets were displayed each minute. Thus, there were 45 targets and 75 non-targets within a 15 minute monitoring period. Each participant was asked to monitor the computer screen for a period of 15 minutes while listening to a newscast in English through headphones. A news-broadcast, rather than a simple acoustic signal, was used so that the participant will get attracted to switching attention from the task at hand as verbal code is known to affect performance (Martin, Wogalter and Forlano, 1988). The participants were told that there would be no questions related to what they heard through the headphones. Participants had to press a key when a target appeared on the screen. Each participant was given a short practice session with five targets/non-targets of less than a minute. Thereafter, the test was conducted and the software automatically recorded the number of hits, misses, correct rejections and false alarms. Even though 'The Test Battery for Attentional Performance (TAP)' (Zoccolotti et al. 2000), is able to capture both the intensity as well as the selectivity aspects of attention (König et al. 2005), the alerteness test measure in TAP, which is a simple reaction test measure, is unable to predict the speed component of multitasking. In our test, the intensity aspect is a capture of the alertness of the subject to distinguish the target image from noise and the selectivity 
aspect refers to the ability of the subject to be focused on the computer monitor as it displays targets and/or noise while listening to a news broadcast.

In relation to cognitive abilities that determine performance, Riding and Rayner (2000) have shown that there is a relationship between cognitive style or the preferred or habitual way an individual addresses a problem and human performance. Torenvliet et al. (2000) found that a holistic cognitive style as measured by the Spy Ring History Test (SRT) (Jonassen and Grabowski 1993, Pask and Scott 1972) was a significant predictor of performance on ecological interfaces. In our study, cognitive style was measured using the Wholist-Analytic (WA) and the Verbal-Imagery (VI) scores from the English version of the Cognitive Style Analysis (CSA) test (Riding and Rayner 2000). This is a computer-presented test with three subsets. The first subset elicits judgments on 24 statements (conceptual items) on whether or not two things are of the same type (for example, are "GOLF and TEA POT the same TYPE”?) and on 24 statements (appearance items) on whether or not the items are the same color (for example, are "BLOOD and TOMATO the same COLOR"?). The second subset elicites judgments on whether or not two geometrical shapes are the same. The third subset includes questions on whether or not a simple shape is included in a complex shape. The ratio of the reaction time for the second subset to the reaction time the third subset gives the Wholist-Analytic ratio, which determines "whether an individual tends to organize information in wholes or parts" (Riding 1991). The reaction time for the conceptual items divided by the reaction time in the appearance items in the first subset gives the Verbal-Imagery ratio and determines "whether an individual is inclined to represent information during thinking verbally or in mental pictures” (Riding 1991). 
The CSA, digit span test and attention test were administered on a Pentium III 700 MHz computer.

\subsubsection{Multitasking}

Arithmetic tasks (Backs et al. 1995, Balci and Aghazadeh 2003, Luximon and Goonetilleke 2001, Ryu and Myung 2005) and search tasks (Courtney and Shou 1985, Drury and Clement 1978, Gramopadhye et al. 2002) have been used in many studies related to cognitive ability. Thus, the experimental task used to test multitasking ability included 20 math problems and 20 search tasks under three conditions:

1. Unpaced: participant-determined order with no time limit;

2. Paced: participant-determined order with a time limit (five minutes) for both the calculations and the search tasks; and

3. Ordered Paced: computer-paced search task combined with participantdetermined calculations for a total duration of five minutes. In this condition, participants could decide on the sequence to perform the math problems, but one search screen was shown every 15 seconds (a search screen for 10 seconds followed by a blank screen for five seconds). The subjects could switch to the search task or ignore the search task when it appeared. However, they were not allowed to call-back any search screens they missed if they were focused on calculations at the time. If a participant is able to switch between tasks then handling such a paced task with a given sequence should not cause any deterioration in performance.

The calculation task was a paper and pencil task. The twenty math problems included four levels of difficulty (addition of a two-digit number to a one-digit number; subtraction of a two-digit number from a two-digit number; subtraction of a 
three-digit number from a four-digit number; multiplication of a three-digit number by a two-digit number) (Luximon and Goonetilleke 2001) with five repetitions of each level. In the search task, each participant was asked to find and count the number of letter 'Es' found in a noisy display of 'Fs' and presented on a PowerPoint slide (see figure 1). All Fs and Es were randomly distributed within the $190 \mathrm{~mm} \times 187 \mathrm{~mm}$ area of the screen. Each slide had between 0 and 5 Es among the one-hundred Fs. There were four slides with 1, 2, 3, or 4 Es and two slides with 0 or 5 Es among the 20 slides (that is, $\mathrm{p}_{\mathrm{i}}=0.2$ for $\mathrm{i}=1$ to 4 and $\mathrm{p}_{\mathrm{i}}=0.1$ for $\mathrm{i}=0$ or 5 ). Participants were asked to do the search and the math calculations as quickly and as correctly as possible.

[Insert figure 1 about here]

\subsection{Experimental design}

As 48 participants performed all the cognitive ability tests, this part of the experiment can be considered to be a one-way ( $2 \mathrm{M} / \mathrm{P}$ groups (monochrons and polychrons)) factorial design. The dependent variables for this analysis were the IPI perception score, the IPI memory score, the IPI judgment score, the attention score, and the cognitive style score.

The multitasking part of the study was a $2 \mathrm{M} / \mathrm{P}$ groups (monochrons or polychrons) $\times 3$ conditions (related to pacing) full factorial experiment. A Latinsquare-like design was used to counter-balance the three task conditions with four monochrons and four polychrons in each group. Speed, accuracy, and the associated switching strategy of the searching and calculation tasks were the dependent variables. 


\subsection{Procedure}

Participants were required to perform the individual ability tests one by one in the following sequence: CSA test, Judgment test (I.P.I.), Digit span, Memory test (I.P.I.) and Perception test (I.P.I.). After completing the individual abilities test, participants had a half-hour break and then they performed a practice trial prior to the search and calculation tasks. The practice trial had 20 calculations and 20 search tasks, which the participant was allowed to do in any order. At the end of the practice trial, the participants were given feedback on their completion time and performance accuracy. As the experimental tasks were rather straightforward, each participant performed only two trials in each condition before moving to the next condition. The first trial was considered to be a practice trial and only data from the second trial were analyzed. Finally, the attention test with auditory noise was completed by the participants.

\section{Results and analysis}

The demographic information of the 48 participants is presented in table 1 . The simple statistics of the MPAI3 score and IPV score of the 48 participants are given in table 2 .

[Insert tables 1 and 2 about here]

\subsection{Individual abilities}


Statistics on all ability tests are given in table 2. After the participants completed the CSA test, each participant was asked to translate 95 English words that appeared in the first part of the CSA into Chinese. The statistics on the CSA test (see table 2) show that, on average, participants did not understand $24.58 \%$ of the English words. One of the participants was unable to explain the meaning of $40 \%$ of the English words. Thus, the Verbal-Imagery ratio may not be an accurate representation of participant ability in this particular test setting as some participants did not understand the meanings of English words.

The intercorrelations between the M/P score and the individual ability scores are presented in table 3.

[Insert table 3 about here]

In the CSA test, the one-way (M/P) ANOVA showed that there was no significant difference in Wholist-Analytic ratio $(\mathrm{F}(1,46)=0.68, \mathrm{p}=0.4142)$ and the VerbalImagery ratio $(\mathrm{F}(1,46)=0.53, \mathrm{p}=0.4705)$ between the monochrons and polychrons. Similarly, there were no significant differences in IPI Perception $(F(1,46)=0.65$, $\mathrm{p}=0.4250)$, IPI Judgment $(\mathrm{F}(1,46)=0.60, \mathrm{p}=0.4435)$ and IPI Memory $(\mathrm{F}(1,46)=0.37$, $\mathrm{p}=0.5452)$ and the digit span test $(\mathrm{F}(1,46)=0.82, \mathrm{p}=0.3703)$ between monochrons and polychrons.

Even though there was no significant difference in the number of false alarms in the attention test $(\mathrm{F}(1,46)=0.29, \mathrm{p}=0.5921)$ between monochrons and polychrons, the number of hits between the two groups was significantly different $(F(1,46)=4.21$, $\mathrm{p}=0.0459$ ) with monochrons having a significantly higher number of hits (mean = 43.5) compared with polychrons (mean $=41.33)$. 


\subsection{Multitasking}

The independent variables for this task were the $\mathrm{M} / \mathrm{P}$ group and the three conditions related to the time constraint of the test. The dependent variables for the 20 search tasks were calculated as follows:

Percentage of correct searches $\left(\mathrm{S}_{\text {correct }}\right)$

$=($ Number of screens correctly searched $/ 20) \times 100$

Percentage of screens searched $\left(S_{\text {done }}\right)=($ Number of screens searched $/ 20) \times 100$

Search count error $\left(\mathrm{S}_{\text {error }}\right)$

$=\sum_{\mathrm{n}=1}^{20} \mid$ number of 'E's given by participant - correct number of 'E's $\mid$

in slide ' $\mathrm{n}$ ', where $\mathrm{n}=$ slide number

A correct search was defined when the participant indicated the correct number of Es on one slide. The number of correct and incorrect searches was related to the number of screens.

The performance measures for the math calculations were as follows:

Percentage of correct calculations ( $\left.\mathrm{M}_{\text {correct }}\right)$

$=($ Number of correct calculations $/ 20) \times 100$

Percentage of calculations attempted ( $\left.\mathrm{M}_{\mathrm{done}}\right)$

$=($ Number of calculations attempted $/ 20) \times 100$

The composite measures that accounted for both search and calculations were:

Total percentage of correct search and math calculation $\left(\mathrm{T}_{\text {correct }}\right)$ 
$=(($ Number of correct searches + number of correct calculations $) / 40) \times 100$

Total percentage of search and calculation attempted $\left(\mathrm{T}_{\text {done }}\right)$

$=(($ Number of screens searched + number of calculation attempted $) / 40) \times 100$

Total performance time $=$ Total time for finishing search and calculation tasks

The strategy measure was the number of switches between the search task and calculation task $\left(\mathrm{N}_{\text {switch }}\right)$.

The two-way (M/P and condition) ANOVA for each of the variables is shown in table 4. There were no significant differences in accuracy between monochrons and polychrons on the search task. However, the polychrons showed significantly higher accuracy than the monochrons in the calculations (see tables 4 and 5) and, as a result, their total accuracy was significantly higher. Even though there was no significant difference between monochrons and polychrons in the percentage of screens searched ( $\left.\mathrm{S}_{\text {done }}\right)$ and the percentage of calculations attempted $\left(\mathrm{M}_{\text {done }}\right)$, the totals ( $\left.\mathrm{T}_{\text {done }}\right)$ of each were significantly different, with polychrons attempting more search and calculation tasks than monochrons did (see tables 4 and 5). The polychrons also had significantly more number of switches between the two tasks.

[Insert tables 4 and 5 about here]

The three conditions significantly differed (see table 4). Participants spent more time in the unpaced condition, as time was unlimited, compared with the two paced conditions. Hence it is no surprise that the performance scores under the unpaced condition were higher than under the paced conditions (see table 6). In addition, the 
number of switches in the ordered paced condition was larger than those in the other two conditions, which may be explained by the nature of the task. The ordered paced condition included a computer-paced search task and participants had to switch from the calculation task to the search task if they wanted to attempt the search tasks. The interaction between the conditions and $\mathrm{M} / \mathrm{P}$ groups on the number of switches was significant $(\mathrm{F}(2,138)=3.12, \mathrm{p}=0.0475)$ (see table 4$)$ and is plotted in figure 2. Due to the differences between unpaced and paced conditions and also due to the presence of interactions, separate ANOVAs were performed for the unpaced condition and for the two paced conditions. The results are presented in tables 7 and 8.

[Insert tables 6, 7 and 8 about here]

[Insert figure 2 about here]

In the unpaced condition (see table 7), monochrons are marginally significantly different from polychrons on the number of switches $\left(\mathrm{N}_{\text {switch }}\right)(\mathrm{p}=0.0509)$ between the search and calculation tasks. Other than this marginal effect, there were no other significant differences between monochrons and polychrons in the unpaced condition. The results from the two-way ANOVA analysis of both paced conditions (see table 8) differed from the results of the unpaced condition. Polychrons made a higher number of switches ( $\left.\mathrm{N}_{\text {switch }}\right)$ between the two tasks $(\mathrm{F}(1,92)=4.44, \mathrm{p}=0.0379)$ compared with monochrons (with means $\mathrm{P}=17.375$; and $\mathrm{M}=13.438$ ). Results from the analysis of the two total variables $\left(\mathrm{T}_{\text {correct }}\right.$ and $\mathrm{T}_{\text {done }}$ ) were different as well $\left(\mathrm{T}_{\text {correct }}\right.$ for $\mathrm{P}=69.271$ and $\mathrm{M}=62.656$; $\mathrm{T}_{\text {done }}$ for $\mathrm{P}=85.279$ and $\left.\mathrm{M}=79.375\right)$. In other words, polychrons did more and achieved better performance in these two conditions in the presence of a time constraint. The ANOVA results also showed that the there were significant 
differences between the two paced conditions on the percentage of screens searched $\left(\mathrm{S}_{\mathrm{done}}\right.$ for paced condition $=71.146$ and ordered paced $\left.=87.917\right)$, the search count error ( $S_{\text {error }}$ for paced condition $=19.583$ and ordered paced $=13.646$ ), the total percentage of searches and calculations attempted $\left(T_{\text {done }}\right.$ for paced condition $=77.604$ and ordered paced $=87.500)$ and the number of switches $\left(\mathrm{N}_{\text {switch }}\right.$ for paced condition $=$ 1.438 and ordered paced $=29.375)$. Participants attempted more search and calculation tasks and had fewer search count errors under ordered paced than under paced condition. At the same time, participants switched between the two search and math calculation tasks in ordered paced more than in paced condition. Our results agree with Wright's (1988) observation that individuals are motivated to perform multiple simultaneous tasks under tight time constraints.

\section{Discussion and conclusion}

In this study, a series of cognitive ability and cognitive style tests were administered to identify potential relationships between time use behaviours and cognitive ability and strategies for performing multiple tasks. The extent of monochronicity and polychronicity was determined using two established scales, MPAI3 (Lindquist et al. 2001) and IPV (Bluedorn et al. 1999). The results showed that there were no differences in memory, judgment, perception, and cognitive styles between monochrons and polychrons. In addition, the correlations among the M/P scores and the cognitive test scores were relatively low $(\mathrm{r}<|0.5|)$ as well, as similarly reported by Conte and Jacobs (2003). These observations suggest that a person's ability to do many things at a time may not be related to memory, judgment, perception and cognitive style. The data do not support hypothesis 1 for these variables. 
However, in the attention task, monochrons had a higher number of hits when compared to polychrons, possibly because monochrons like to concentrate on one thing at a time (Hall 1989). Monochrons were focused on the monitoring task in the attention test and were possibly not distracted by the English news they heard. Polychrons, on the other hand, tend to like interruptions (Hall and Hall 1990) and hence may have been distracted by what they heard through the earphones. As a result, they may have missed the targets more often than the monochrons did. Some of the polychrons indicated to the experimenter that they switched their attention to other things during the attention test. When people have to allocate their attention to more than one task, performance in some or all of the tasks may be reduced, due to limited resources (Wickens and Hollands 2000). The experiment had two tasks but performance was assessed only in one, and this was clearly made known to the participants. Since performance on the auditory task was not measured in this study, further study is needed to quantify differences between monochrons and polychrons in attention allocation. Even though attention has been related to performance (Arthur et al. 1995, Gopher et al. 1989, Mane and Donchin 1989, Frederiksen and White 1989), differences in attention have not yet been investigated from the standpoint of individual differences. Polychronicity quite clearly appears to be related to a person's task-switching abilities. Monochrons seem to perform well when the primary task is important.

The multitasking experiment yielded interesting results. Performance under the three conditions (unpaced, paced condition and ordered paced) significantly differed with performance under unpaced condition significantly better than under the other two conditions, possibly due to the unlimited amount of time allowed to do the tasks under the unpaced condition or perhaps because of a speed-accuracy tradeoff. Under 
the two paced conditions, participants did not finish all the search and calculation tasks within the 5 minute period and thus the accuracy was lower. This indicates that the unpaced condition was relatively easier than the two paced conditions. Moreover, participants switched more often in the ordered paced condition than unpaced and paced conditions. The math calculations were on paper and the search task was computer-based. Thus, participants tended to group the math calculations and separate the search task whenever they could. This is a possible explanation for the lower number of switches under the unpaced and paced conditions. However, the search task in ordered paced condition was computer-paced with a fixed time interval. Participants were somehow 'forced' to switch to the search task if they wanted to improve their performance.

The M/P differences in strategy and performance reported previously (Haase et al. 1979, Hall 1989, Lee 1999, Zhang et al. 2005) were observed here as well. Polychrons switched between the math task and the search task more than monochrons did (see tables 5 and 9). Performance on the two tasks was evaluated separately as well as together. The results of the two-way ANOVA indicated that there were no differences in accuracy in the search task between monochrons and polychrons (see table 4). This result may be due to the fact that the available time was the same for monochrons as well as for polychrons depending on how they prioritized their two tasks. Since the search screen appeared at a certain time in ordered paced condition, it may be that all participants considered the search tasks to have a higher priority. Polychrons performed significantly better in the math task (mean of $\mathrm{P}=84.236$; mean of $\mathrm{M}=79.306$ ) and, as a result, achieved higher accuracy in the “total” variable, $\mathrm{T}_{\text {correct }}$ (mean of $\mathrm{P}=75.451$; mean of $\mathrm{M}=71.215$ ). Even though the attempts of the individual search and math tasks were not different, the totals ( $\left.\mathrm{T}_{\text {attempt }}\right)$ 
showed that polychrons attempted more tasks than monochrons did (mean of $\mathrm{P}=90.486$; mean of $\mathrm{M}=86.250$ ). These results support Hall’s (1989) hypothesis that monochrons feel disoriented and perform worse than polychrons whenever there are many things to do in addition to attending to the high priority tasks first.

In summary, polychrons performed significantly better than monochrons on the calculations and total task performance. There were no significant interactions between the M/P groups and the conditions except for the number of switches ( $\left.\mathrm{N}_{\text {switch }}\right)$ $(p=0.0509)$. The one-way ANOVA results showed that there were no significant differences between monochrons and polychrons in unpaced condition (see table 7). But, monochrons and polychrons were different in $\mathrm{T}_{\text {correct }}$ and $\mathrm{T}_{\text {done, }}$ and $\mathrm{N}_{\text {switch }}$ in the two paced conditions (see table 8). Our analyses indicate the possibility of a difficulty threshold below which there is no difference between monochrons and polychrons (for example, unpaced condition) but beyond which there are performance differences between monochrons and polychrons (such as in the two paced conditions), thus supporting Ishizaka, Marshall and Conte's (2001) contention that, at low levels of difficulty or complexity, polychrons and monochrons may have similar performance. These results confirm hypothesis 2 .

In studying fault management, Moray and Rotenberg (1989) mention that people prefer to deal with faults serially rather than switching between faults in fault management situations. Such a strategy is characteristic of monochrons and hence the concept of cognitive lock-up may be unique to monochrons. If a measure such as the MPAI3 or IPV was used in the Moray and Rotenberg (1989) study, it may have given much more insight into their results and the outlier subjects.

Gonzalez (2004) investigated the hypotheses that a person's ability to deal with time constraints improves with practice and that practice should help individuals 
perform better. She was surprised by the result that there was no improvement in performance even after extensive practice under time constraints. Based on our study and our previous work (Zhang et al. 2005), we believe that without considering the characteristic of time use behaviour that distinguishes people as monochrons or polychrons, it is not useful to report performance differences under different training situations because a person's time use behaviour cannot change significantly unless the task becomes relatively easier. It is true that operator selection is against the basic principles of human factors and ergonomics, which are concerned with fitting the task to the person. However, understanding the characteristics that help a person perform efficiently under various conditions will allow designers to design better with an optimum task allocation between people and machines. It is always worthwhile to understand if training alone can improve performance or if designers need to specify special selection criteria for operators. Like cognitive style, which is a stable trait (Jonassen and Grabowski 1993) that cannot be learned, time use behaviour may be another trait that ought to be considered especially in situations when the availability of time to attend to tasks may be limited.

The number of switches between the tasks clearly seems to be strongly related to polychronicity. We are unaware of any measure that can predict the change-over between tasks. Torenvliet et al. (2000) found that the Wholist cognitive style was related to performance. In this study, we found that participants exhibiting polychronicity have somewhat better total performance on more than one task in time constrained conditions. With unlimited time, the performance differences between monochrons and polychrons did not occur. In other words, with increasing task difficulty, the differences in performance between monochrons and polychrons may increase. Further study is needed to define the relationship between $\mathrm{M} / \mathrm{P}$ performance 
and task difficulty. Factors such as task priority may play a role as well (Hall 1989). Ishizaka et al. (2001) has alluded to a potential interaction between task difficulty and priority with the performance by monochrons and polychrons. More study is needed to pinpoint these performance differences between the two groups.

\section{Acknowledgements}

This study was made possible through funding obtained from a Direct Allocation Grant (DAG) at HKUST.

\section{References}

Arthur, Jr.W., Strong, M.H., Jordan, J.A., Williamson, J.E., Shebilske, W.L. and Regian, J.W., 1995, Visual attention: Individual differences in training and predicting complex task performance. Acta Psychologica, 88(1), pp. 3-23.

BaCKs, R.W., Ryan, A.M., Wilson, G.F. and SwAIn, R.A., 1995, Topographic EEG changes across single-to-dual task performance of mental arithmetic and tracking. In Proceedings of the Human Factors and Ergonomics Society $39^{\text {th }}$ Annual Meeting, pp. 953 (Santa Monica, CA: Human Factors and Ergonomics Society).

Balci, R. and AghazadeH, F., 2003, The effect of work-rest schedules and type of task on the discomfort and performance of VDT users. Ergonomics, 46, pp. 455465.

Beare, A.N., Dorris, R.E., Kozinsky, E.J., Manning, J.J. and HaAs, P., 1983, Criteria for safety related nuclear power plant operator actions: initial simulator 
to field data calibration (Rep. No. NUREG-CR-3092). Washington, DC: US Nuclear Regulatory Commission.

Benson, L. and BEACH, L.R., 1996, The effects of time constraints on the prechoice screening of decision options. Organizational Behavior and Human Decision Processes, 67(2), pp. 222-228.

Bluedorn, A.C., Kalliath, T.J., Strube, M.J. and Martin, G.D., 1999, Polychronicity and the Inventory of Polychronic Values (IPV): The development of an instrument to measure a fundamental dimension of organizational culture. Journal of Managerial Psychology, 14(3-4), pp. 205-230.

Brown, J.S., McDonald, J.L., Brown, T.L. and Carr, T.H., 1988, Adapting to processing demands in discurse production: The case of handwriting. Journal of Experimental Psychology: Human Perception and Performance, 14, pp. 45-59.

ConTe, J.M. and GINTOFT, J.N., 2005, Polychronicity, big five personality dimensions and sales performance. Human Performance, 18(4), pp. 427-444.

CONTE, J.M. and JACOBS, R.R., 2003, Validity evidence linking polychronicity and big five personality dimensions to absence, lateness and supervisory performance ratings. Human Performance, 16(2), pp. 107-129.

Courtney, A.J. and ShOU, C.H., 1985, Simple measures of visual-lobe size and search performance. Ergonomics, 28(9), pp. 1319-1331.

DelBRIDGE, K.A., 2000, Individual differences in multi-tasking ability: exploring a nomological network. Unpublished doctoral dissertation, Michigan State University, East Lansing.

DruRy, C.G. and Clement, M.R., 1978, The effect of area, density and number of background characters on visual search. Human Factors, 20, pp. 597-602. 
FLeishman, E.A., 1991, Manual for the ability requirement scales. Palo Alto, CA: Consulting Psychologists Press.

Fleishman, E.A. and ReILly, M.E., 1992, Handbook of human abilities. Palo Alto, CA: Consulting Psychologists Press.

FREDERIKSEN, J.R. and WHITE, B.Y., 1989, An approach to training based on principled task decomposition. Acta Psychologica, 71, pp. 89-146.

GONZALEZ, C., 2004, Learning to make decisions in dynamic environments: Effects of time constraints and cognitive abilities. Human Factors, 46(3), pp. 449-460.

GoONetilleke, R.S., 1990, Humans in complex control tasks: Mental model development and use. Unpublished doctoral dissertation, State University of New York at Buffalo, New York.

GoOnetiLleKe, R.S., SHIH, H.M. and Sze, Y.Y., 1999, Memory span: The effect of calculation method and presentation mode. International Journal of Cognitive Ergonomics, 3(4), pp. 271-287.

GopHER, D., 1992, The skill of attention control: Acquisition and execution of attention strategies. In Attention and performance XIV: Synergies in experimental psychology, artificial intelligence, and cognitive neuroscience, D. Meyer and S. Korenblum (Eds.) (Cambridge, MA: MIT Press).

Gopher, D., WeIL, M. and Siegel, D., 1989, Practice under changing priorities: AN approach to the training of complex skills. Acta Psychologica, 71, pp. 147-178.

Gramopadhye, A.K., Drury, C.G., Jiang, X. and Sreenivasan, R., 2002, Visual search and visual lobe size: can training on one affect the other? International Journal of Industrial Ergonomics, 30, pp. 181-195.

HaAse, R.F., LeE, D.Y. and BANKS, D.L., 1979, Cognitive correlates of polychronicity. Perceptual and Motor Skills, 49, pp. 271-282. 
HALL, E.T., 1959, The silent language. New York: Fawcett Publications.

HaLL, E.T., 1989, The hidden dimension. New York: Anchor Press.

HALl, E.T. and HALL, M.R., 1990, Understanding cultural differences. Yarmouth, Me: Intercultural Press.

Hirshkowitz, M., De la Cueva, L. and Herman, J. H., 1993, The multiple vigilance test. Behavior Research Methods, Instruments, and Computers, 25(2), pp. 272-275.

I.P.I., 1981, Manual for Judgment: a measure of logical thinking and problem solving ability. Champaign, Illinois: IPI.

I.P.I., 1981, Perception: test examiner's manual. Champaign, Illinois: IPI.

I.P.I., 1984, Memory: test examiner’s manual. Champaign, Illinois: IPI.

IshiZAKA, K, MARSHALL, S.P. and CONTE, J.M., 2001, Individual differences in attentional strategies in multitasking situations. Human Performance, 14(4), pp. 339-358.

Jonassen, D.H. and GrabowsKi, B.L., 1993, Handbook of individual differences, learning and instruction. Mahwah, NJ: Erlbaum.

KÖNIG, C.J., BÜHneR, M. and MüRling, G., 2005, Working memory, fluid intelligence, and attention are predictors of multitasking performance, but polychronicity and extraversion are not. Human Performance, 18(3), pp. 243-266.

LEE, H., 1999, Time and information technology: monochronicity, polychronicity and temporal symmetry. European Journal of Information Systems, 8, pp. 16-26.

Lindquist, J.D., Knieling, J. and KaUfman-Scarborough, C., 2001, Polychonicity and consumer behavior outcomes among Japanese and U.S. students: A study of response to culture in a U.S. university setting. In Proceedings of the Tenth Biennial World Marketing Congress (City Hall Cardiff, United Kingdom). 
Luximon, A. and Goonetilleke, R.S., 2001, A Simplified Subjective Workload Assessment Technique. Ergonomics, 44(3), pp. 229-243.

MAdJAR, N. and OldhAM, G.R., 2006, Task rotation and polychronicity: Effects on individuals' creativity. Human Performance, 19(2), pp. 117-131.

MARTIN, R.C., WOGALTER, M.S., and FORLANO, J.G., 1988, Reading comprehension in he presence of unattended speech and music. Journal of Memory and Language, 27, 382-398.

Mane, A. M. and Donchin, E., 1989, The Space Fortress game. Acta Psychologica, 71, pp. 17-22.

MAUle, A. J. and EDlAND, A.C., 1997, The effects of time pressure on human judgement and decision making. In Decision making: Cognitive models and explanations, R. Ranyard, W.R. Crozier and O. Svenson (Eds.), pp. 189-204 (London: Routledge).

Moray, N. and Rotenberg, I., 1989, Fault management in process control: eye movements and action. Ergonomics, 32(11), pp. 1319-1342.

PASK, G. and ScotT, B.C., 1972, Learning styles and individual competence. International Journal of Man-Machine Studies, 4, pp. 217-253.

Plocher, T., Goonetilleke, R.S., Zhang, Y. and Liang, S.F.M., 2002, Time orientation across cultures. In Proceedings of the 4th Annual International Workshop on Internationalisation of Products and Systems (IWIPS) - Designing for Global Markets 4, pp. 23-31 (Austin, Texas, United States).

Preacher, K.J., MacCallum, R.C., Rucker, D.D. and NiceWander, W.A., 2005, Use of the extreme groups approach: A critical reexamination and new recommendations. Psychological Methods, 10(2), pp. 178-192. 
RATSEgaRY, H. and LANDY, F.J., 1993, The interactions among time urgency, uncertainty and time pressure. In Time pressure and stress in human judgment and decision making, O. Svenson and A.J. Maule (Eds.), pp. 217-239 (New York: Plenum).

RIDING, R.J., 1991, Cognitive Styles Analysis Users’ Guide. Birmingham: Learning and training technology.

Riding, R.J. and Rayner, S.G., 2000, Cognitive Styles. Stamford, Conn.: Ablex Publishing Corp.

RYU, K. and MyunG, R., 2005, Evaluation of mental workload with a combined measure based on physiological indices during a dual task of tracking and mental arithmetic. International Journal of Industrial Ergonomics, 35(100), pp. 991-1010.

Torenvliet, G. L., Jamieson, G. A. and Vicente, K. J., 2000, Making the most of ecological interface design: The role of individual differences. Applied Ergonomics, 31, pp. 395-408.

WANG, M.J.J., Sharit, J. and DruRY, C.G., 1991, Fuzzy set evaluation of inspection performance. International Journal of Man-Machine Studies, 35, pp. 587-596.

WiCKens, C.D. and Hollands, J.G., 2000, Engineering psychology and human performance. Upper Saddle River, New Jersey: Prentice-Hall.

Wright, L., 1988, The Type A behavior pattern and coronary artery disease. American Psychologist, 43, pp. 2-14.

Zhang, Y., Goonetilleke, R.S., Plocher, T. and Liang, S.F.M., 2005, Timerelated behaviour in multitasking situations. International Journal of HumanComputer Studies, 62, pp. 425-455.

Zoccolotti, P., Matano, A., Deloche, G., Cantagallo, A., Passadori, A. and LeClerCQ, M., 2000, Patterns of attentional impairement following closed head injury: A collaborative European Study. Cortex, 36, pp. 93-107. 
Table 1. Demographic information on the participants $(\mathrm{N}=48)$

\begin{tabular}{|c|c|c|c|c|}
\hline & \multicolumn{2}{|c|}{ M group } & \multicolumn{2}{|c|}{ P group } \\
\hline & Hong Kong & Mainland & Hong Kong & Mainland \\
\hline & Chinese & Chinese & Chinese & Chinese \\
\hline Total number & 12 & 12 & 12 & 12 \\
\hline \multicolumn{5}{|l|}{ Gender } \\
\hline Male & 6 & 6 & 8 & 5 \\
\hline Female & 6 & 6 & 4 & 7 \\
\hline \multicolumn{5}{|l|}{ Education } \\
\hline Undergraduate & 11 & 1 & 9 & 1 \\
\hline Postgraduate & 1 & 11 & 3 & 11 \\
\hline \multicolumn{5}{|l|}{ Age } \\
\hline Average & 21.83 & 24.83 & 22.25 & 26.17 \\
\hline SD & 2.37 & 1.75 & 1.48 & 2.79 \\
\hline
\end{tabular}


Table 2. Statistics on the results of the tests of the 48 participants

\begin{tabular}{|c|c|c|c|c|c|c|}
\hline & & $\begin{array}{c}\mathrm{M} / \mathrm{P} \\
\text { group }\end{array}$ & Minimum & Maximum & Mean & SD \\
\hline \multirow{4}{*}{$\begin{array}{r}\mathrm{M} / \mathrm{P} \\
\text { scores }\end{array}$} & \multirow{2}{*}{ MPAI3 } & M & 1 & 3 & 2.21 & 0.64 \\
\hline & & $\mathrm{P}$ & 5 & 7 & 5.89 & 0.68 \\
\hline & \multirow{2}{*}{ IPV } & M & 1.4 & 3 & 2.16 & 0.51 \\
\hline & & $\mathrm{P}$ & 4.9 & 6 & 5.25 & 0.32 \\
\hline \multirow{5}{*}{ CSA } & Wholist-Analytic & M & 0.8 & 2.16 & 1.33 & 0.36 \\
\hline & ratio & $\mathrm{P}$ & 0.78 & 2.66 & 1.43 & 0.46 \\
\hline & Verbal -Imagery & M & 0.76 & 1.34 & 1.06 & 0.15 \\
\hline & ratio & $\mathrm{P}$ & 0.78 & 1.2 & 1.03 & 0.11 \\
\hline & $\begin{array}{c}\text { Percentage of } \\
\text { unknown words }\end{array}$ & All & 8.42 & 40.00 & 24.58 & 8.09 \\
\hline \multirow{2}{*}{\multicolumn{2}{|c|}{ I.P.I. Perception }} & M & 23 & 46 & 31.67 & 4.94 \\
\hline & & $\mathrm{P}$ & 24 & 44 & 32.92 & 5.79 \\
\hline \multirow{2}{*}{\multicolumn{2}{|c|}{ I.P.I. Judgment }} & M & 26 & 46 & 31.67 & 4.94 \\
\hline & & $\mathrm{P}$ & 24 & 48 & 36.5 & 6.13 \\
\hline \multirow{8}{*}{$\begin{array}{l}\text { I.P.I. } \\
\text { Memory }\end{array}$} & Subtest 1 & M & 8 & 16 & 13.63 & 2.00 \\
\hline & Visual memory & $\mathrm{P}$ & 7 & 16 & 12.96 & 2.27 \\
\hline & Subtest 2 & M & 8 & 13 & 11 & 1.91 \\
\hline & Verbal memory & $\mathrm{P}$ & 7 & 15 & 10.79 & 2.25 \\
\hline & Subtest 3 & M & 5 & 11 & 8 & 1.47 \\
\hline & Numbers memory & $\mathrm{P}$ & 4 & 11 & 8.17 & 2.08 \\
\hline & \multirow{2}{*}{ Total } & M & 23 & 38 & 32.63 & 3.81 \\
\hline & & $\mathrm{P}$ & 25 & 40 & 31.92 & 4.23 \\
\hline \multirow{2}{*}{\multicolumn{2}{|c|}{ Digit span }} & M & 8 & 13 & 9.98 & 1.18 \\
\hline & & $\mathrm{P}$ & 8 & 13 & 10.33 & 1.51 \\
\hline \multirow{4}{*}{ Attention } & \multirow{2}{*}{ Number of hits } & M & 38 & 45 & 43.5 & 1.93 \\
\hline & & $\mathrm{P}$ & 23 & 45 & 41.33 & 4.80 \\
\hline & \multirow{2}{*}{$\begin{array}{l}\text { Number of false } \\
\text { alarm }\end{array}$} & M & 0 & 12 & 3.13 & 3.58 \\
\hline & & $\mathrm{P}$ & 0 & 23 & 3.79 & 4.88 \\
\hline
\end{tabular}


Table 3. Inter-correlations among the different tests $(\mathrm{N}=48)$

\begin{tabular}{|c|c|c|c|c|c|c|c|c|c|c|c|}
\hline & & \multicolumn{2}{|c|}{ M/P score } & \multicolumn{2}{|c|}{ CSA } & \multicolumn{3}{|c|}{ I.P.I. Tests } & \multirow{2}{*}{$\begin{array}{l}\text { Digit } \\
\text { span }\end{array}$} & \multicolumn{2}{|c|}{ Attention test } \\
\hline & & MPAI3 & IPV & WA Ratio & VI Ratio & Perception & Judgment & Memory & & $\begin{array}{l}\text { Number } \\
\text { of Hits }\end{array}$ & $\begin{array}{c}\text { Number of } \\
\text { False Alarms }\end{array}$ \\
\hline & MPAI3 & 1 & & & & & & & & & \\
\hline & IPV & $0.96 *$ & 1 & & & & & & & & \\
\hline & WA Ratio & 0.08 & 0.07 & 1 & & & & & & & \\
\hline CSA & VI Ratio & -0.12 & -0.12 & 0.18 & 1 & & & & & & \\
\hline & Perception & 0.13 & 0.13 & -0.11 & -0.03 & 1 & & & & & \\
\hline & Judgment & 0.08 & 0.12 & -0.05 & -0.16 & $0.53^{*}$ & 1 & & & & \\
\hline & Memory & -0.07 & -0.12 & 0.12 & 0.10 & $0.29^{* *}$ & $0.28 * * *$ & 1 & & & \\
\hline Digit span & & 0.07 & 0.07 & -0.12 & 0.002 & 0.22 & 0.13 & $0.25^{* * *}$ & 1 & & \\
\hline Attention & $\begin{array}{l}\text { Number } \\
\text { of Hits }\end{array}$ & $-0.28 * * *$ & $-0.26 * * *$ & $-0.36^{* *}$ & 0.06 & $0.26 * * *$ & $0.39 *$ & 0.11 & 0.13 & 1 & \\
\hline test & $\begin{array}{c}\text { Number of } \\
\text { False Alarms }\end{array}$ & 0.13 & 0.12 & 0.08 & $0.27 * * *$ & -0.07 & $-0.27 * * *$ & 0.05 & -0.12 & -0.09 & 1 \\
\hline
\end{tabular}

Note: ${ }^{*} \mathrm{p}<0.01{ }^{* *} \mathrm{p}<0.05 * * * \mathrm{p}<0.1$ 
Table 4. Two-way ANOVA of M/P and condition

for $\mathrm{S}_{\text {correct }}, \mathrm{S}_{\text {done, }} \mathrm{S}_{\text {error }}, \mathrm{M}_{\text {correct }}, \mathrm{M}_{\text {done, }}, \mathrm{T}_{\text {correct }}, \mathrm{T}_{\text {done }}, \mathrm{N}_{\text {switch }}$ and Time $(\mathrm{N}=48)$

\begin{tabular}{|c|c|c|c|c|c|c|c|c|c|c|c|c|c|c|c|c|c|c|c|}
\hline \multirow[b]{3}{*}{ Source } & \multirow[b]{3}{*}{$\mathrm{DF}$} & \multicolumn{6}{|c|}{ Search } & \multicolumn{4}{|c|}{ Math calculation } & \multicolumn{8}{|c|}{ Total } \\
\hline & & \multicolumn{2}{|c|}{$\mathrm{S}_{\text {correct }}$} & \multicolumn{2}{|c|}{$\mathrm{S}_{\text {done }}$} & \multicolumn{2}{|c|}{$\mathrm{S}_{\text {error }}$} & \multicolumn{2}{|c|}{$\mathrm{M}_{\text {correct }}$} & \multicolumn{2}{|c|}{$\mathrm{M}_{\text {done }}$} & \multicolumn{2}{|c|}{$\mathrm{T}_{\text {correct }}$} & \multicolumn{2}{|c|}{$\mathrm{T}_{\text {done }}$} & \multicolumn{2}{|c|}{$\mathrm{N}_{\text {switch }}$} & \multicolumn{2}{|c|}{ Time } \\
\hline & & $\begin{array}{c}\mathrm{F} \\
\text { Value }\end{array}$ & $\operatorname{Pr}>F$ & $\begin{array}{c}\mathrm{F} \\
\text { Value }\end{array}$ & $\operatorname{Pr}>F$ & $\begin{array}{c}\mathrm{F} \\
\text { Value }\end{array}$ & $\operatorname{Pr}>F$ & $\begin{array}{c}\mathrm{F} \\
\text { Value }\end{array}$ & $\operatorname{Pr}>F$ & $\begin{array}{c}\mathrm{F} \\
\text { Value }\end{array}$ & $\operatorname{Pr}>F$ & $\begin{array}{c}\mathrm{F} \\
\text { Value }\end{array}$ & $\operatorname{Pr}>F$ & $\begin{array}{c}\mathrm{F} \\
\text { Value }\end{array}$ & $\operatorname{Pr}>\mathrm{F}$ & $\begin{array}{c}\text { F } \\
\text { Value }\end{array}$ & $\operatorname{Pr}>\mathrm{F}$ & $\begin{array}{c}\mathrm{F} \\
\text { Value }\end{array}$ & $\operatorname{Pr}>F$ \\
\hline MP & 1 & 1.65 & 0.2010 & 3.47 & 0.0645 & 2.55 & 0.1124 & 4.04 & 0.0464 & 1.29 & 0.2584 & 7.58 & 0.0067 & 5.89 & 0.0166 & 5.62 & 0.0191 & 1.01 & 0.3160 \\
\hline Condition & 2 & 51.93 & $<.0001$ & 27.92 & $<.0001$ & 42.63 & $<.0001$ & 15.64 & $<.0001$ & 18.64 & $<.0001$ & 91.95 & $<.0001$ & 55.08 & $<.0001$ & 217.36 & $<.0001$ & 94.45 & $<.0001$ \\
\hline $\begin{array}{c}\text { MP } \\
\times \text { condition }\end{array}$ & 2 & 1.32 & 0.2716 & 1.22 & 0.2998 & 1.09 & 0.3389 & 0.52 & 0.5985 & 0.32 & 0.7248 & 2.39 & 0.0950 & 1.74 & 0.1796 & 3.12 & 0.0475 & 1.01 & 0.3659 \\
\hline Error & 138 & & & & & & & & & & & & & & & & & & \\
\hline
\end{tabular}

Note: Significant results $(\mathrm{p}<0.05)$ are shown in bold. 
Table 5. Comparison of $\mathrm{M} / \mathrm{P}$ means for $\mathrm{M}_{\text {correct }}, \mathrm{T}_{\text {correct, }} \mathrm{T}_{\text {done }}$ and $\mathrm{N}_{\text {switch }}(\mathrm{N}=48)$

\begin{tabular}{cccc}
\hline & & Polychrons & Monochrons \\
\hline $\mathrm{M}_{\text {correct }}$ & Mean & 84.236 & 79.306 \\
$\mathrm{~T}_{\text {correct }}$ & Mean & 75.451 & 71.215 \\
$\mathrm{~T}_{\text {done }}$ & Mean & 90.486 & 86.250 \\
$\mathrm{~N}_{\text {switch }}$ & Mean & 12.306 & 9.319 \\
\hline
\end{tabular}


Table 6. The Student-Newman-Keuls test results for $\mathrm{S}_{\text {correct }}, \mathrm{S}_{\text {done }}, \mathrm{S}_{\text {error }}, \mathrm{M}_{\text {correct }}, \mathrm{M}_{\text {done, }}$, $\mathrm{T}_{\text {correct }}, \mathrm{T}_{\text {done }}, \mathrm{N}_{\text {switch }}$ and Time $(\mathrm{N}=48)$. An underline indicates no difference between conditions.

\begin{tabular}{|c|c|c|c|}
\hline & Unpaced & Paced & Ordered paced \\
\hline $\mathrm{S}_{\text {correct }}$ & 84.688 & 53.542 & 56.458 \\
\hline $\mathrm{S}_{\text {done }}$ & 100.000 & 71.146 & 87.917 \\
\hline$S_{\text {error }}$ & 3.542 & 19.583 & 13.646 \\
\hline $\mathbf{M}_{\text {correct }}$ & 91.458 & 77.396 & 76.458 \\
\hline $\mathbf{M}_{\text {done }}$ & 100.000 & 84.063 & 87.083 \\
\hline $\mathrm{T}_{\text {correct }}$ & 88.073 & 65.469 & 66.458 \\
\hline $\mathrm{T}_{\text {done }}$ & 100.000 & 77.604 & 87.500 \\
\hline $\mathrm{N}_{\text {switch }}$ & 1.625 & 1.438 & 29.375 \\
\hline Time & 9.034 & 5.000 & 5.000 \\
\hline
\end{tabular}


Table 7. One-way ANOVA of unpaced condition for the dependent variables $\mathrm{S}_{\text {correct, }}, \mathrm{S}_{\text {error }}, \mathrm{M}_{\text {correct, }}, \mathrm{T}_{\text {correct, }} \mathrm{N}_{\text {switch }}$ and Time (N=48)

\begin{tabular}{|c|c|c|c|c|c|c|c|c|c|c|c|c|c|}
\hline \multirow[b]{3}{*}{ Source } & \multirow[b]{3}{*}{ DF } & \multicolumn{4}{|c|}{ Search } & \multirow{2}{*}{\multicolumn{2}{|c|}{$\begin{array}{l}\text { Math calculation } \\
\qquad \mathrm{M}_{\text {correct }}\end{array}$}} & \multicolumn{6}{|c|}{ Total } \\
\hline & & \multicolumn{2}{|c|}{$\mathrm{S}_{\text {correct }}$} & \multicolumn{2}{|c|}{$S_{\text {error }}$} & & & \multicolumn{2}{|c|}{$\mathrm{T}_{\text {correct }}$} & \multicolumn{2}{|c|}{$\mathrm{N}_{\text {switch }}$} & \multicolumn{2}{|c|}{ Time } \\
\hline & & F Value & $\operatorname{Pr}>\mathrm{F}$ & F Value & $\operatorname{Pr}>F$ & F Value & $\operatorname{Pr}>\mathrm{F}$ & F Value & $\operatorname{Pr}>F$ & F Value & $\operatorname{Pr}>F$ & F Value & $\operatorname{Pr}>\mathrm{F}$ \\
\hline MP & 1 & 0.73 & 0.3967 & 0.53 & 0.4687 & 0.54 & 0.4642 & 0.06 & 0.8039 & 4.02 & 0.0509 & 1.01 & 0.3195 \\
\hline Error & 46 & & & & & & & & & & & & \\
\hline
\end{tabular}


Table 8. Two-way (M/P × condition) ANOVA of the two paced conditions for the dependent variables $\mathrm{S}_{\text {correct }}, \mathrm{S}_{\mathrm{done}}, \mathrm{S}_{\text {error }}, \mathrm{M}_{\text {correct }}$,

$\mathrm{M}_{\text {done, }} \mathrm{T}_{\text {correct }}, \mathrm{T}_{\text {done }}$ and $\mathrm{N}_{\text {switch }}(\mathrm{N}=48) . \mathrm{p}<0.05$ are shown in bold.

\begin{tabular}{|c|c|c|c|c|c|c|c|c|c|c|c|c|c|c|c|c|c|}
\hline \multirow{4}{*}{ Source } & \multirow{4}{*}{ DF } & \multicolumn{6}{|c|}{ Search } & \multicolumn{4}{|c|}{ Math calculation } & \multicolumn{6}{|c|}{ Total } \\
\hline & & \multicolumn{2}{|c|}{$\mathrm{S}_{\text {correct }}$} & \multicolumn{2}{|c|}{$\mathrm{S}_{\text {done }}$} & \multicolumn{2}{|c|}{$\mathrm{S}_{\mathrm{error}}$} & \multicolumn{2}{|c|}{$\mathbf{M}_{\text {correct }}$} & \multicolumn{2}{|c|}{$\mathrm{M}_{\text {done }}$} & \multicolumn{2}{|c|}{$\mathrm{T}_{\text {correct }}$} & \multicolumn{2}{|c|}{$\mathrm{T}_{\text {done }}$} & \multicolumn{2}{|c|}{$\mathrm{N}_{\text {switch }}$} \\
\hline & & $\mathrm{F}$ & & F & & $\mathrm{F}$ & & F & & $\mathrm{F}$ & & $\mathrm{F}$ & & $\mathrm{F}$ & & $\mathrm{F}$ & \\
\hline & & Value & $\operatorname{Pr}>F$ & Value & $\operatorname{Pr}>\mathrm{F}$ & Value & $\operatorname{Pr}>F$ & Value & $\operatorname{Pr}>F$ & Value & $\operatorname{Pr}>\mathrm{F}$ & Value & $\operatorname{Pr}>\mathrm{F}$ & Value & $\operatorname{Pr}>F$ & Value & $\operatorname{Pr}>F$ \\
\hline MP & 1 & 3.05 & 0.0843 & 3.47 & 0.0655 & 3.11 & 0.0811 & 3.51 & 0.0641 & 1.29 & 0.2594 & 10.33 & 0.0018 & 5.89 & 0.0172 & 4.44 & 0.0379 \\
\hline Condition & 1 & 0.58 & 0.4471 & 12.46 & 0.0006 & 7.89 & 0.0061 & 0.07 & 0.7895 & 0.79 & 0.3761 & 0.23 & 0.6318 & 14.28 & 0.0003 & 223.39 & $<.0001$ \\
\hline MP $\times$ condition & 1 & 0.05 & 0.8278 & 0.46 & 0.4983 & 0.12 & 0.7310 & 0.11 & 0.7443 & 0.00 & 0.9756 & 0.01 & 0.9397 & 0.36 & 0.5523 & 3.46 & 0.0659 \\
\hline Error & 92 & & & & & & & & & & & & & & & & \\
\hline
\end{tabular}




\section{List of figures}

Figure 1. Example of the search task

Figure 2. The interaction between $\mathrm{M} / \mathrm{P}$ and pacing conditions on the number of switches 
Figures

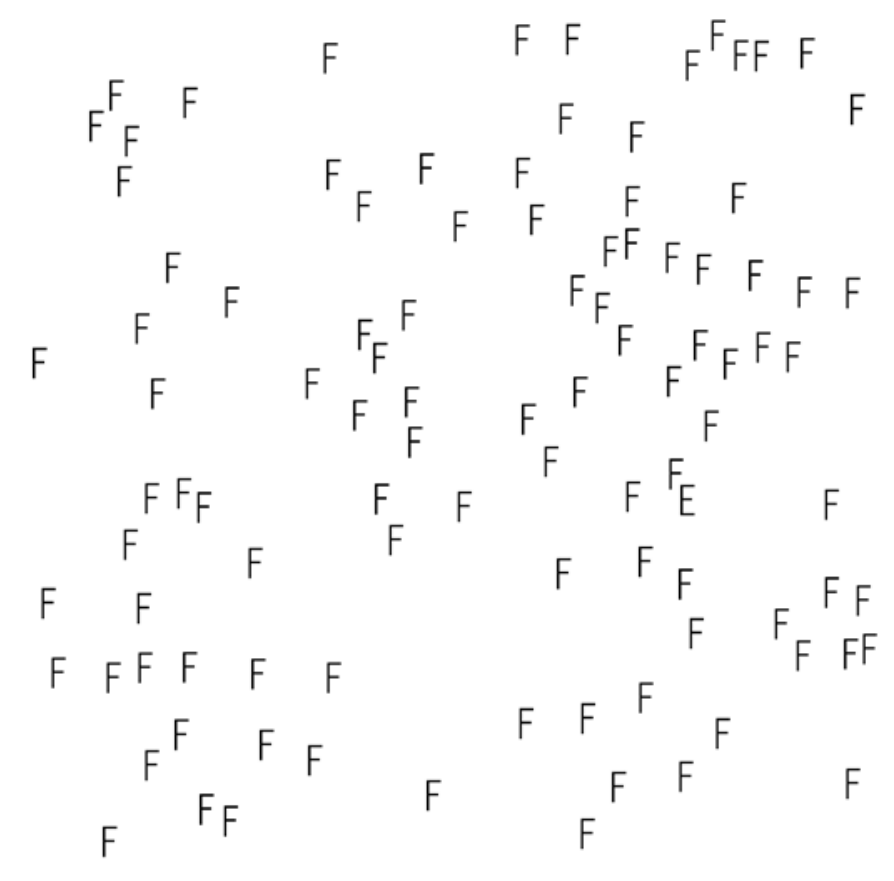

Figure 1. Example of the search task 


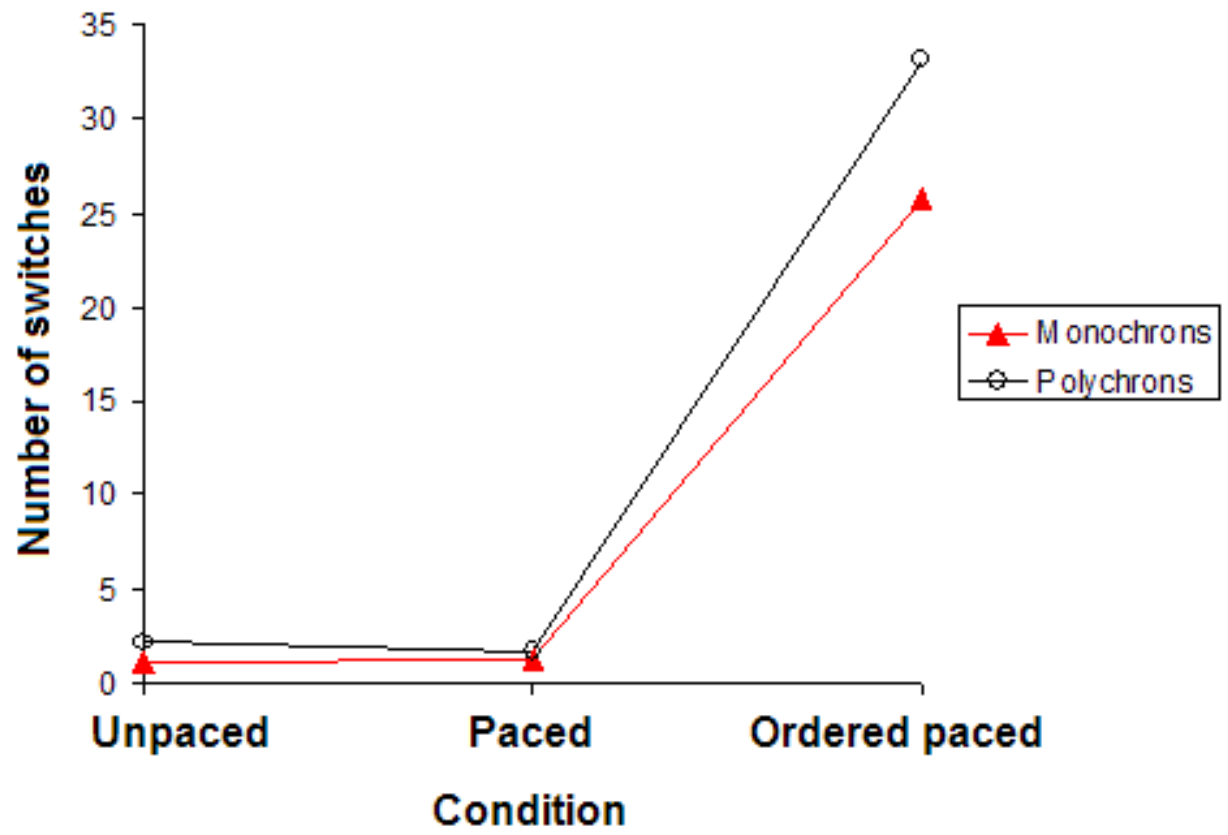

Figure 2. The interaction between $\mathrm{M} / \mathrm{P}$ and pacing conditions on the number of switches 